\title{
Internet authentication and billing (hotspot) system using MikroTik router operating system
}

\author{
Adam Mohammed Saliu ${ }^{1}$, Mohammed Idris Kolo ${ }^{1}$, Mohammed Kudu Muhammad ${ }^{2}$, \\ Lukman Abiodun Nafiu ${ }^{3}$ \\ ${ }^{1}$ Department of Computer Science, Federal University of Technology, Minna, Nigeria \\ ${ }^{2}$ Academic Planning Unit, Federal University of Technology, Minna, Nigeria \\ ${ }^{3}$ Department of Mathematics and Statistics, Federal University of Technology, Minna, Nigeria
}

\section{E-mail address:}

firdaousmama@gmail.com(L. A. Nafiu)

\section{To cite this article:}

Adam Mohammed Saliu, Mohammed Idris Kolo, Mohammed Kudu Muhammad, Lukman Abiodun Nafiu. Internet Authentication and Billing (Hotspot) System Using MikroTik Router Operating System. International Journal of Wireless Communications and Mobile Computing, Vol. 1, No. 1, 2013, pp. 51-57. doi: 10.11648/j.wcmc.20130101.18

\begin{abstract}
This paper is based on using MikroTik Router Operating System (OS) to build an authentication and billing System. This kind of system is always used to create security, billing and administration of users on a network connected to the Internet. It is used to restrict usage and bandwidth allocations to users. A case study of Federal University of Technology, Minna website was considered and it was found that additional stages and radius server services should be incorporated with the antenna design in its hotspot server.
\end{abstract}

Keywords: Internet, Hotspot, MikroTik, Bandwidth and Wireless

\section{Introduction}

The advent of information technology has brought about globalization. The world as we know is fast becoming a global village, where transactions can easily be done from any part of the world with the help of the computer. This achievement owes its credit to the advent of networking. Wireless networks represent one of the most significant inventions in human history with wireless networking as in [1].

According to [2], it is opined that wireless network guarantees access to files regardless of where house and computer facilitates with synchronization of data on a laptop. Using wireless networks makes it so much simpler to send files between computers as compared to the traditional emails or CDs. Moreover, if printer is connected, documents can be written anywhere and finally printed through a printer connected to another computer. In other words, a printer plugged into one of the computers on the network is available to all the computers saving the expense of having multiple printers.

The work in [3] is based on being able to eliminate wires from running all over house is probably the biggest reason why wireless networking plays significant advantage over wired networking. Wired networking costs more and the packed wires make house looking ugly and not safe.

This paper involves the construction of an authentication and billing (Hotspot) server for Federal University of Technology, Minna, Nigeria with the aid of MikroTik Router OS (a Linux-based operating system). Figures 1 and 2 give an overview of operation of a hotspot network and a generalized web login of MikroTik hotspot respectively. This offers a server design that meets the needs of the public in achieving the main aim of true mobility in surfing the internet with imperial management and full administrative control of the network which is one of the distinguishing features of servers as illustrated in figure 3 . 


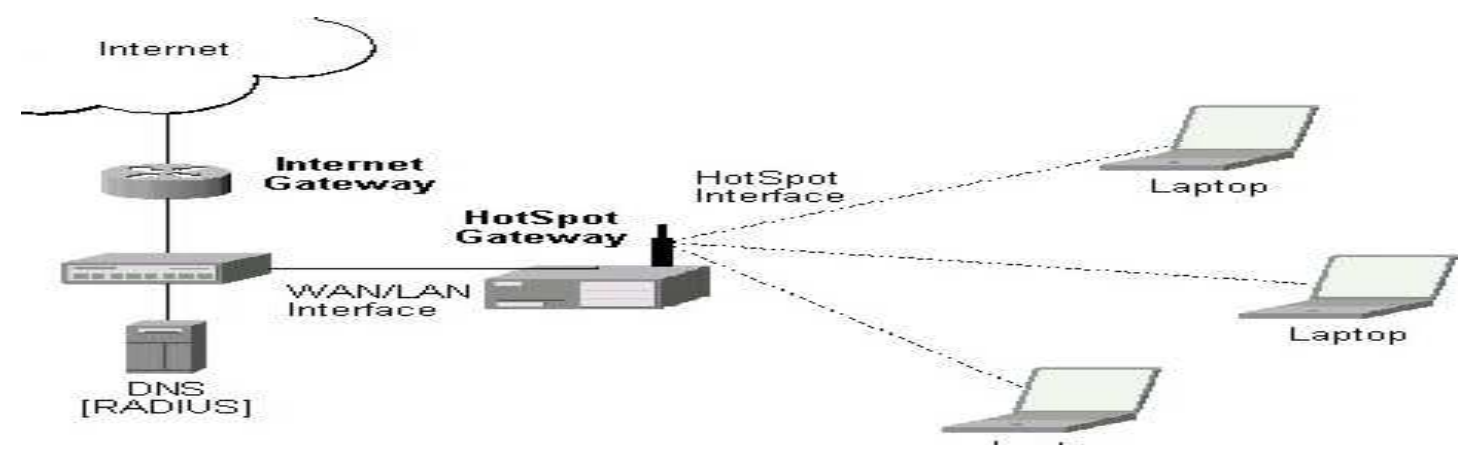

Figure 1. An Overview of Operation of a Hotspot Network

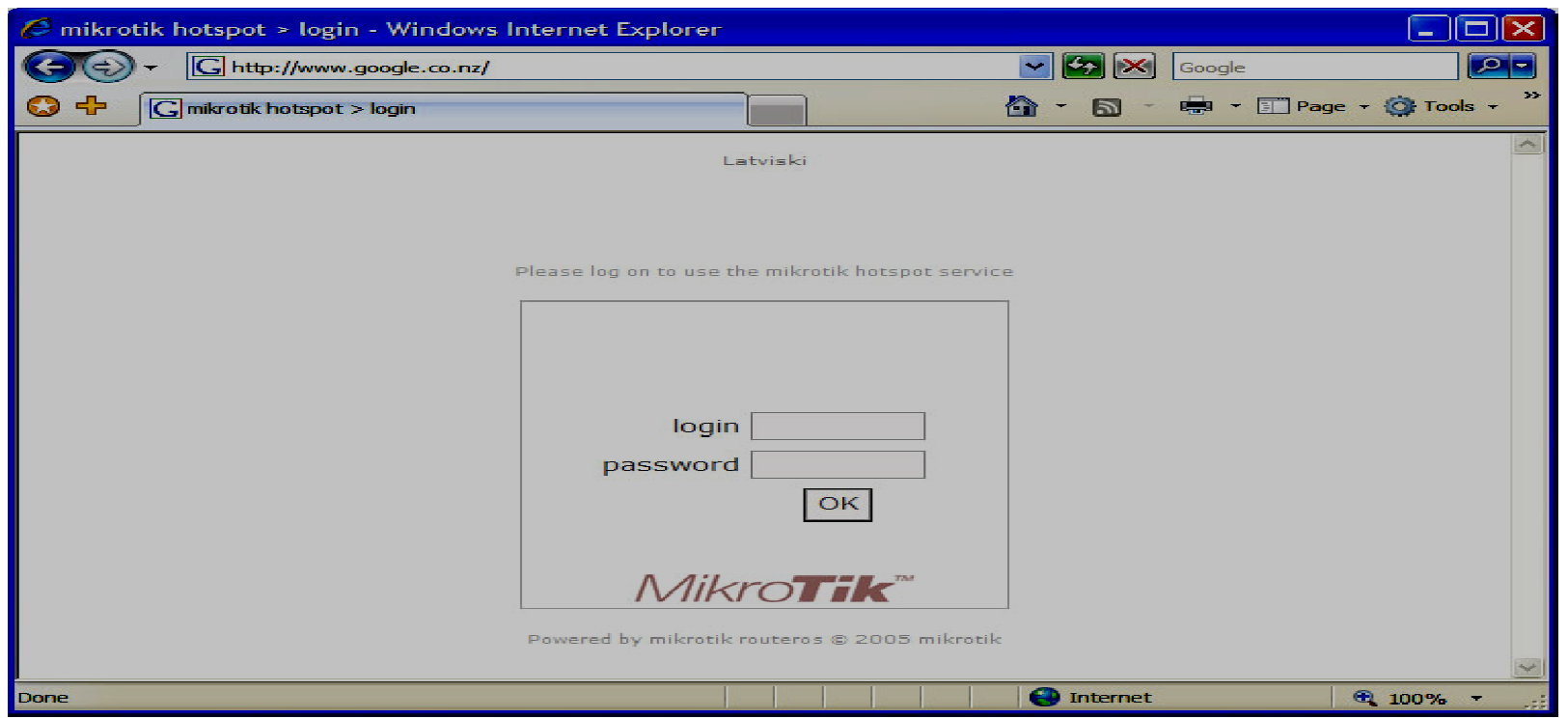

Figure 2. A Generalized Web Login of MikroTik Hotspot

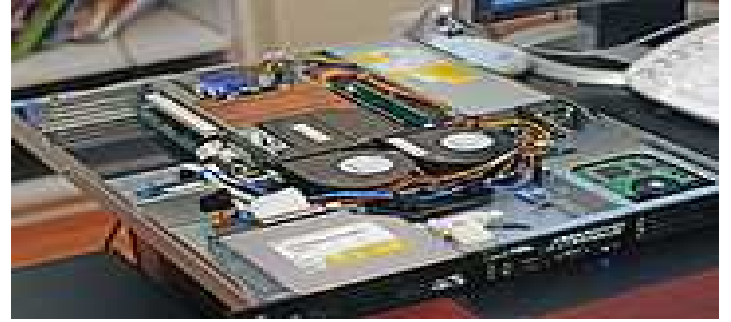

Figure 3. A Server Computer

To begin browsing, a client must go through a registration process with the provider and then enter a username and password in a browser Log-in window that appears on the attempt to open a webpage. Hotspot technology proposes providers to establish and administer a user database, which can be useful for such enterprises as airports, hotels or universities that offer wireless or Ethernet Internet connectivity to employees, students, guests or other groups of users as in [4].

A Wireless Network Interface Controller (WNIC) as given in figure 6 is a network card connected to a radiobased computer network, unlike a regular network interface controller (NIC) which is connected to a wire-based network such as Ethernet. A WNIC is an essential component for wireless desktop computer. This card uses an antenna to communicate through microwaves. A WNIC in a desktop computer usually is connected using the PCI bus (Peripheral Component Interconnect), an industrystandard bus for attaching peripherals to computers. Other connectivity options are USB as given in figures 4 and 5, and card as given in figure 6 based on [5].

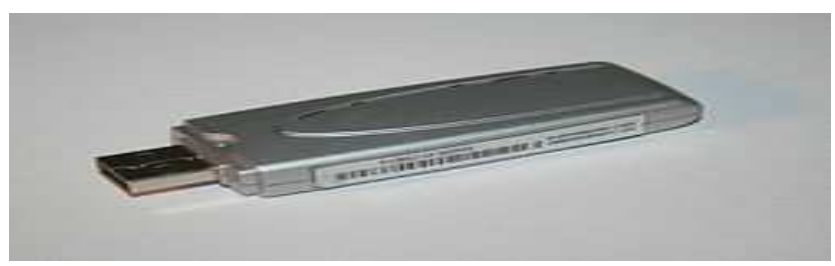

Figure 4. A USB Wireless Network Interface Device

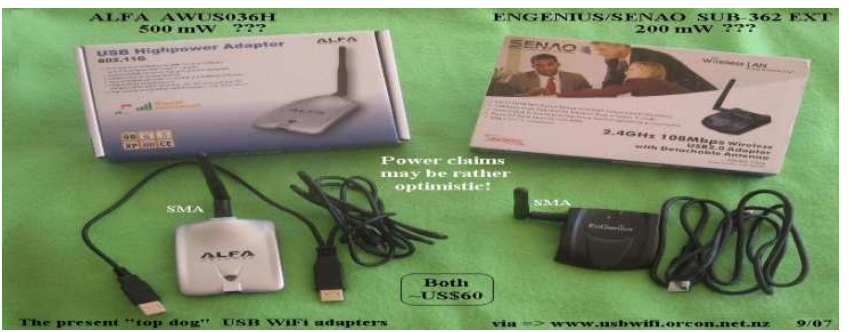

Figure 5. A USB Wireless Network Interface Device 


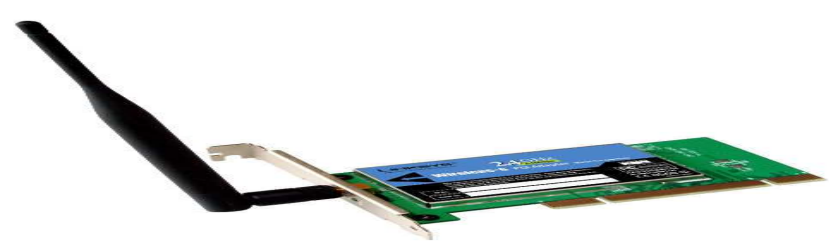

Figure 6. Wireless Network Interface Card

\section{Materials and Methods}

MikroTik Limited known internationally as MikroTik is a Latvian manufacturer of computer networking equipment. The main product of MikroTik is a Linux-based operating system known as MikroTik Router OS. It allows users to turn a selected PC-based machine into a software router, allowing features such as firewall rules, VPN Server and Client, bandwidth shaper Quality of Service, wireless access point and other commonly used features for routing and connecting networks together. The system is also able to serve as a captive-portal based hotspot system (wiki.mikrotik.com).

For this paper, we used Router OS version 2.9.7. The Router OS, combined with its hardware product line, known as MikroTik Router BOARD is marketed at small to medium sized wireless internet service providers, typically providing broadband wireless access in remote areas. We also made use of a MiniPCI to PCI adapter which is an advanced adapter for 3.3v MiniPCI to PCI standard sockets. The adapter is provided in PCI card form with an integrated MiniPCI slot that allows using MiniPCI cards in standard PCI sockets. The MiniPCI adapter includes two LEDs connected to the MiniPCI.

In line with [6], Mini PCI was added to PCI version 2.2 for use in laptops. It uses a 32-bit, 33-MHz bus with powered connections ( $3.3 \mathrm{~V}$ only, $5 \mathrm{~V}$ is limited to $100 \mathrm{~mA}$ ) and support for bus mastering and DMA. The standard size for Mini PCI cards is approximately $1 / 4$ of their full-sized counterparts as found in [5]. As there is limited external access to the card compared to desktop PCI cards, there are limitations on the functions they may perform.
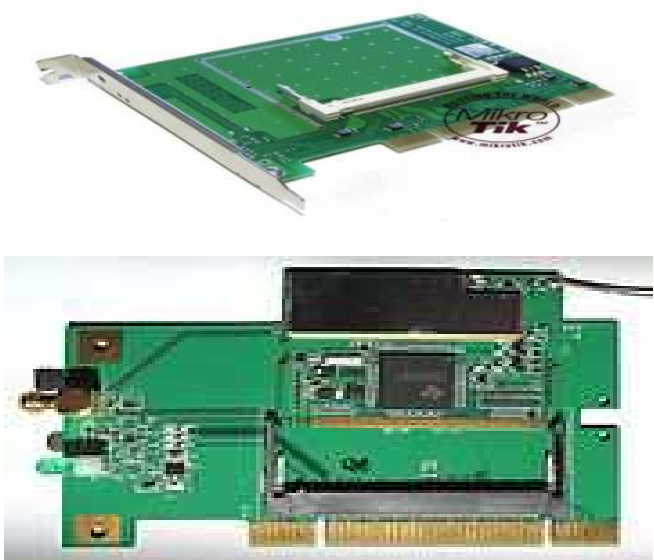

Figure 7. Mikrotik Router Board 11 and MiniPCI-to-PCI Converter Type III

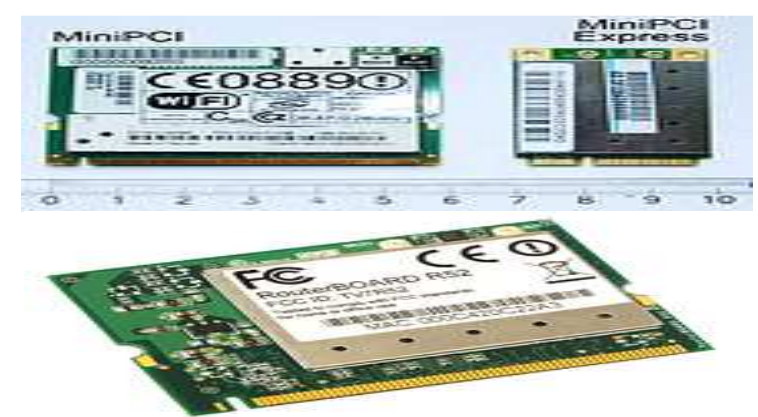

Figure 8. MikroTik MiniPCI and MiniPCI Express cards in comparison

Many Mini PCI devices were developed such as Wi-Fi, Fast Ethernet, Bluetooth, modems, sound cards, cryptographic accelerators, SCSI, IDE/ATA, SATA controllers and combination cards. Mini PCI cards can be used with regular PCI-equipped hardware using Mini PCIto-PCI converters as given in figures 7 and 8 based on [7].

In this paper, construction was carried out in FIVE stages as follows based on [8]:

\subsection{Hardware Configuration Stage}

The hardware units used in this paper are:

(1) A desktop unit consisting of 512RAM, CDROM drive, Hard disk drive of 20Gigabytes, Motherboard with processor of 2.0Gigahertz speed

(2) A laptop with wireless ready and internet ready

(3) MikroTik router board 11 with $400 \mathrm{mw}$ MikroTik MiniPCIcard and 2dbi antenna

(4) MikroTik Router's CD for installation

(5) Microsoft FrontPage CD 2003 package for the web hotspot interface design

\subsection{Software Installation Stage using MikroTik Router OS CD}

The desktop unit is being assembled with keyboard, monitor, mouse and UPS.

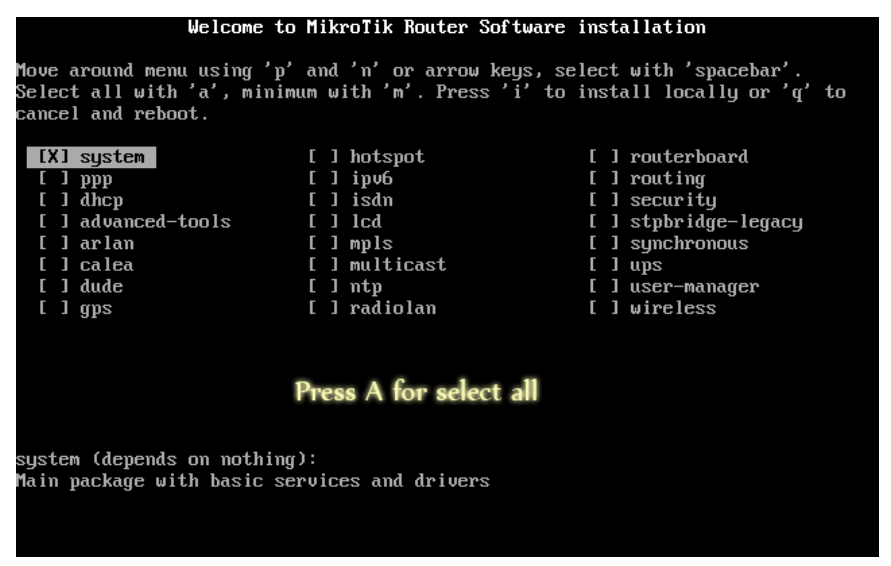

Figure 9. MikroTik Router Software Installation

Press "a" key for select all and then press "i". Then, answer " $n$ " to first question and " $y$ " to second as can be 
seen in figure 9.

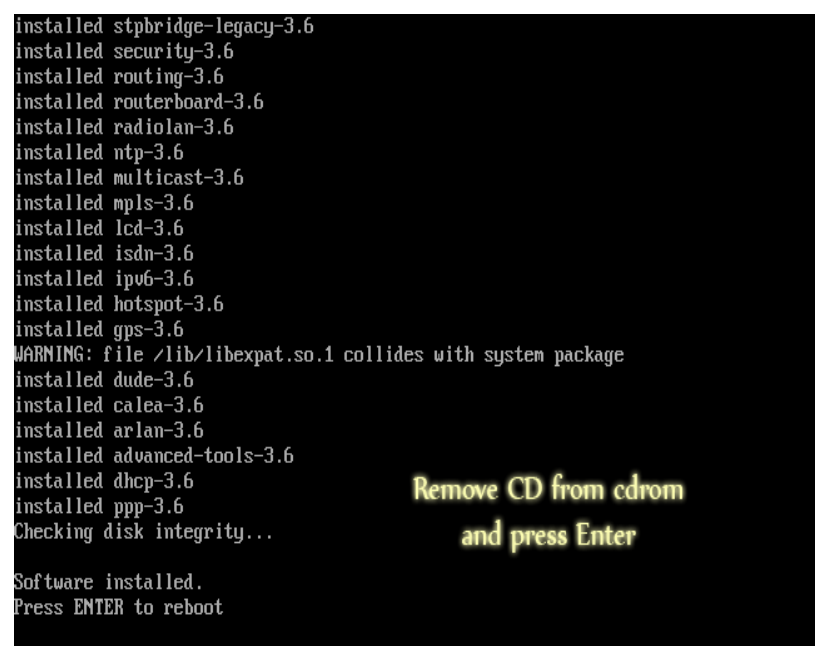

Figure 10. Procedure to Remove CD from CDROM

Installation removes $\mathrm{CD}$ from $\mathrm{CD}-\mathrm{ROM}$ and press "Enter". After rebooting, type "admin" as login and no password required as contained in figure 10.

\subsection{Network Planning and Implementation}

Network planning involves planning of the network IP addresses and subnet address. The IP address for the LAN, as for this paper is concerned with 192.168.8.54, while the subnet address is 255.255.255.0 and gateway is 192.168.8.1. It has two types of network structures: one is a wireless while the other is a LAN network. The addresses listed above are for the LAN network which supplies the Hotspot server with internet. The next planning is for the wireless in which one gets the privilege of choosing the set of IP addresses to use for the wireless network interface. For Federal University of Technology, Minna website as found in [9], we applied 10.5.50.1 as the gateway for the wireless interface while the subnet address remains 255.255.255.0.The DNS still remains 192.168.8.1.

\subsection{Configuration and Test Running}

The following are the initial steps to take after installation is done successfully. The newly installed router OS needs to be initially configured with an IP address through the command line interface prior being able to continue the configuration through the Winbox or web interface. Once the server has been restarted, it boots up with username and password. IP address for the unit can be either statically or dynamically assigned. In this work, we used static IP address. The step to sign IP starts when the server prompts the following MikroTik RouterOS ${ }^{\text {TM }}$ Welcome Screen on the command prompt menu.

\subsection{Hotspot Web Browser Login Window Design}

Press Enter to setup dhcp server. Type "a" to configure IP address and gateway.

Then, key in 192.168.8.54/255.255.255.0 (IP/subnet) and press enter key. Next press g to add default gateway to the

server. Default gateway will be 192.168.8.1. The same process will be used for wireless LAN interface IP configuration but in this case it is represented by WLAN. IP address is 10.5.50.1/255.255.255.0 (IP/Subnet).

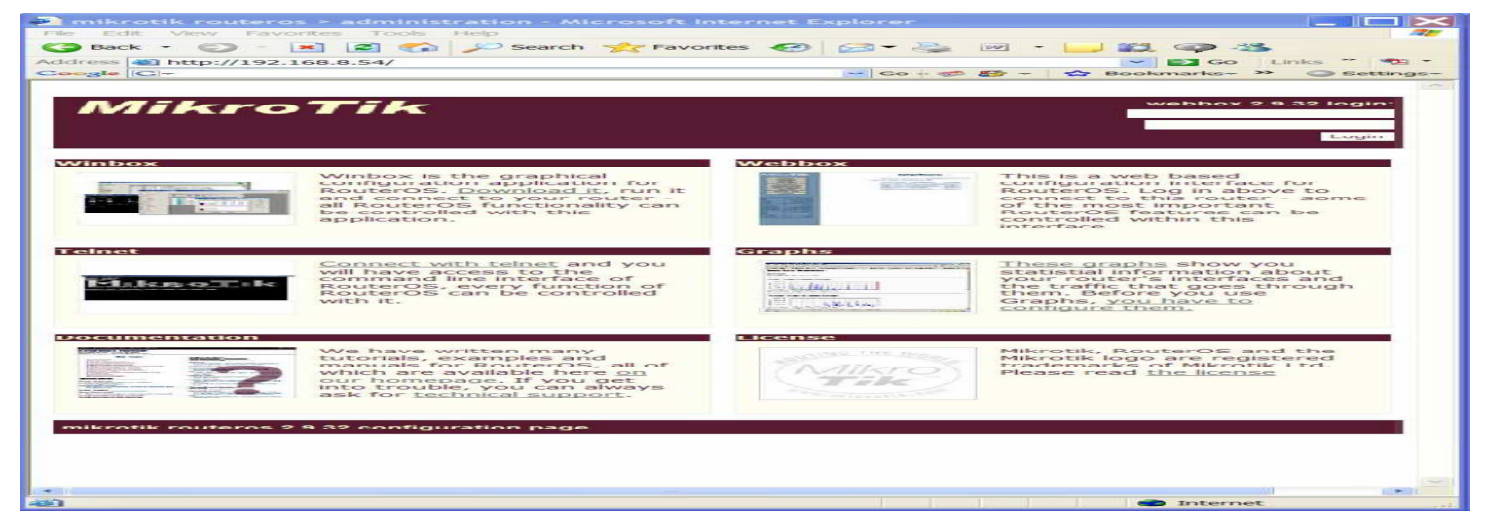

Figure 11. Web interface of MikroTik RouterOS.

Once the web interface of MikroTik Router OS in figure 11 is downloaded, we run it to access the router by entering the LAN IP address, username and password as given in figure 12 .

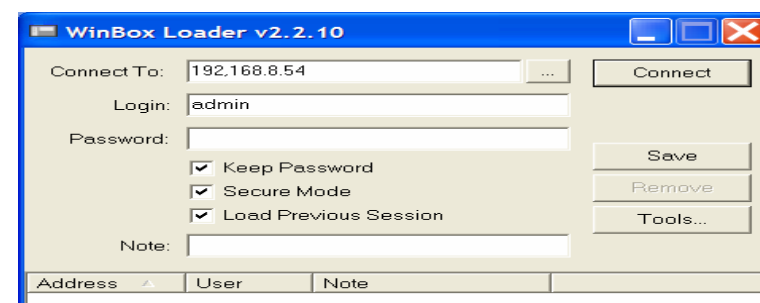

Figure 12. WINBOX Login Interface 
On logging in, the following menu given in figure 13 appears

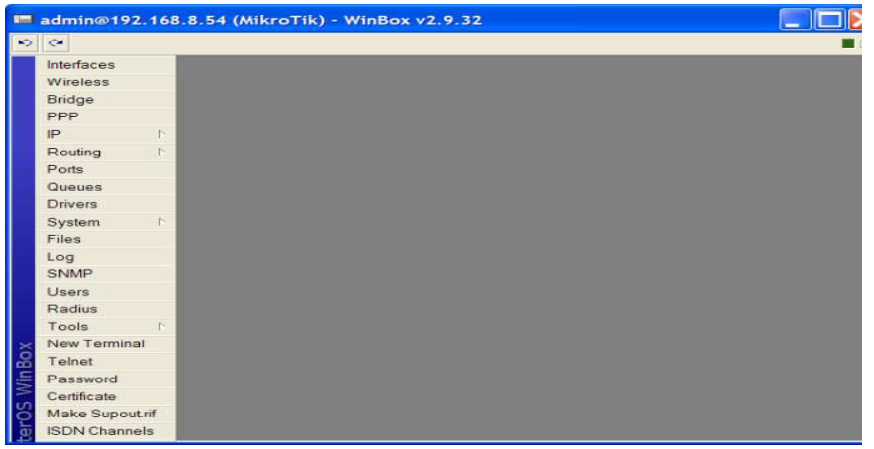

Figure 13. WINBOX full interface

Next is the Hotpot setup given in figure 14. On the left hand menu, click on the + sign to add a hotspot interface.

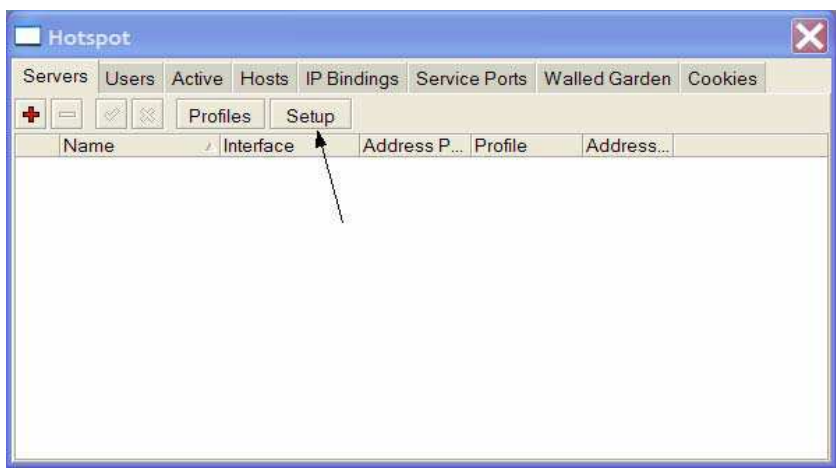

Figure 14. Hotspot setup interface

Click on Setup to select the hotspot interface WLAN1

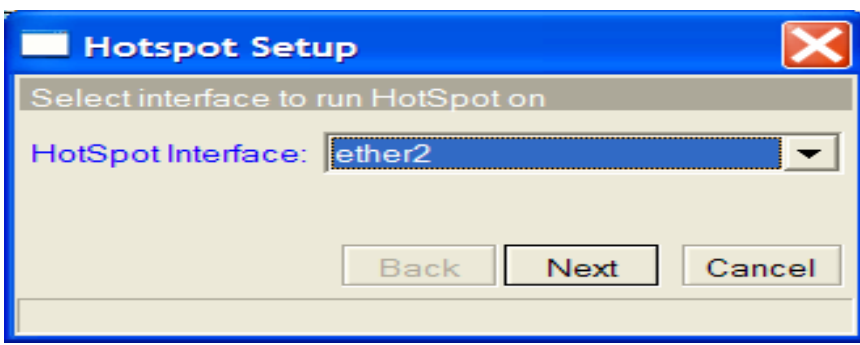

Figure 15. Hotspot Interface Setup1

Select the desire IP address for the Hotspot as given in figure 16

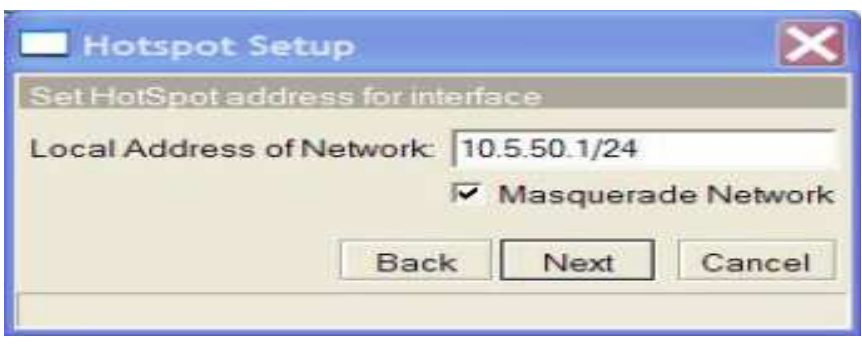

Figure 16. Hotspot Interface Setup 2
Select the IP address range as contained in figure 17

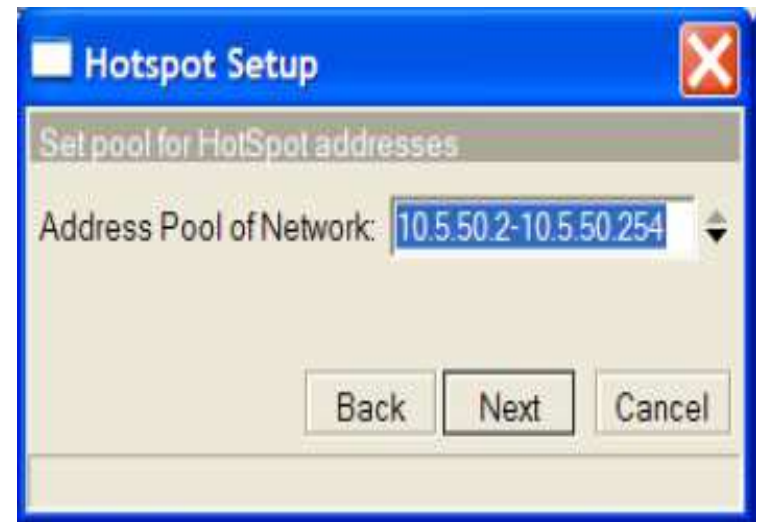

Figure 17. Hotspot Interface Setup 3

Then enter SSL certificate for the MikroTik as contained in figure 18

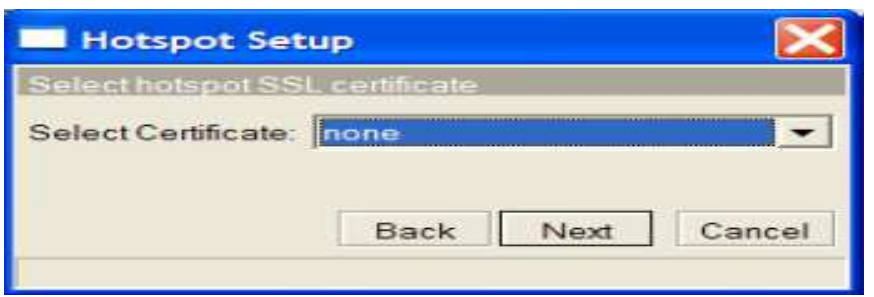

Figure 18. Hotspot Interface Setup 4

Most Hotspot providers will not add their SMTP server to avoid clients registering for short period and using their servers for spam as in figure 20.

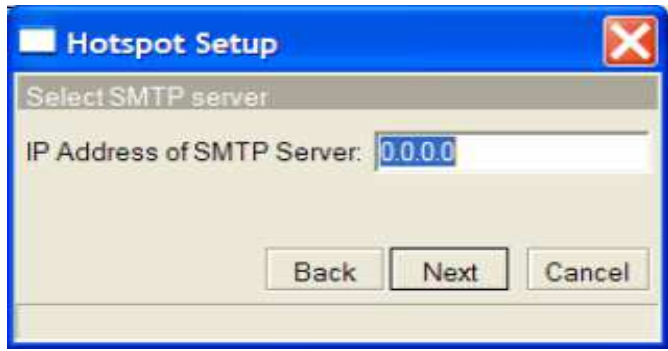

Figure 19. Hotspot Interface Setup 5

Enter the DNS server address for the MikroTik as contained in figure 20

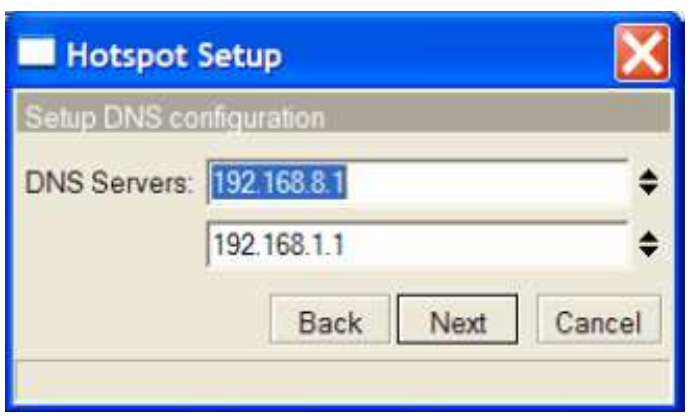

Figure 20. Hotspot Interface Setup 6 
Enter the local DNS name for the MikroTik as given in figure 21

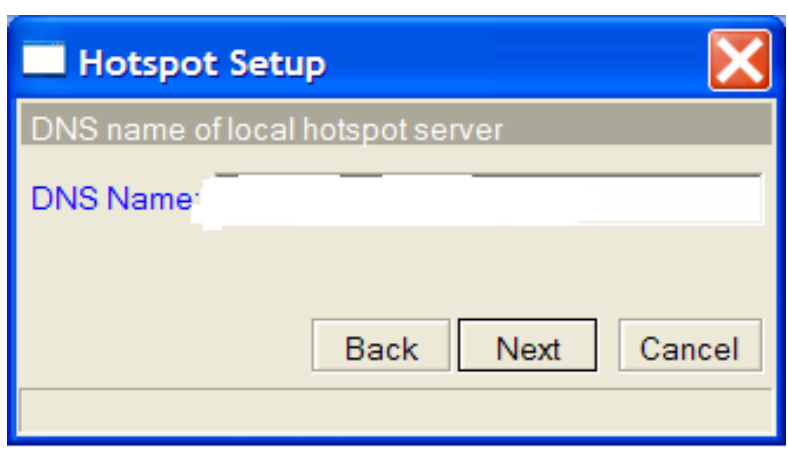

Figure 21. Hotspot Setup 7

Enter an admin hotspot user for local Winbox and Internet account as contained in figure 22. After this step, hotspot setup is completed successfully.

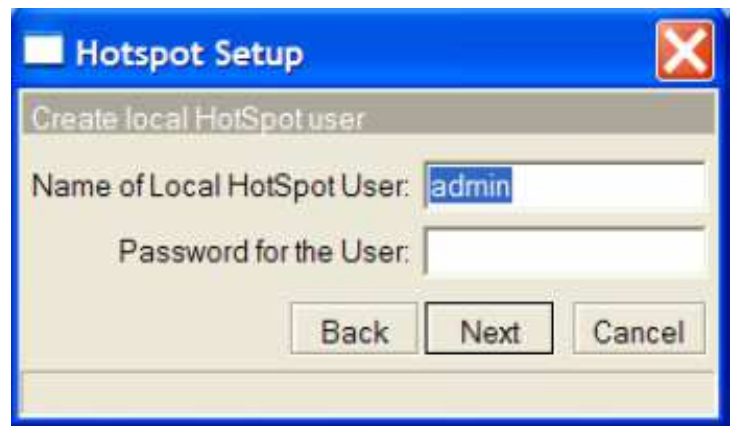

Figure 22. Hotspot Setup 8

\section{Results}

To edit the login, one needs to get the HTML page file that is responsible for displaying the MikroTik default hotspot web browser login. To get this file, fill the username on the web browser of the laptop with admin and password left blank. Once it logs in, type ftp://10.5.0.1 on the internet address bar. It prompts a login box again asking for username and password. Open the folder and copy the file "login.html" to the desktop of the laptop. Minimize the browser and open the file "login.html" with already installed Microsoft FrontPage in the laptop. With this web design skills, we came up with the design given in figure 23 .

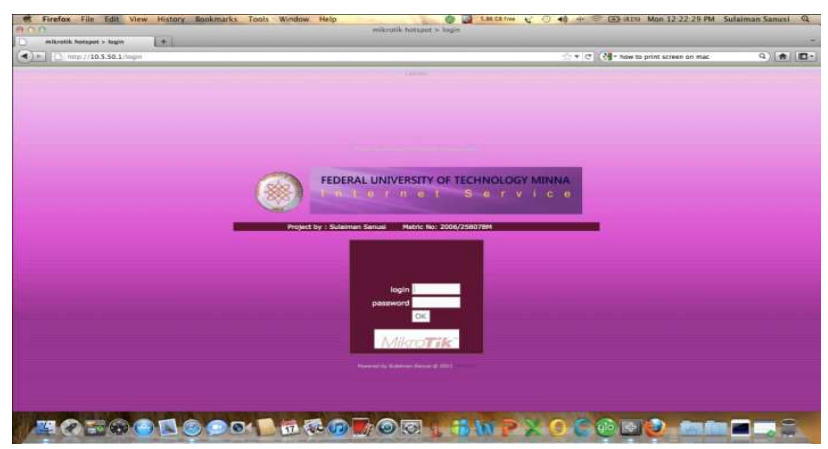

Figure 23. A Customized Design Page for FUT, Minna Internet Service

\section{Discussion}

The MikroTik Router OS version 2.9.7 used for this paper was well studied, proper understanding on how the system operates and troubleshooting was done. All important network terminologies and strategic network infrastructural planning were considered and put in place before project execution. The MikroTik hotspot server designed in this work has only one wireless interface due to consideration of where it would be placed in the department so that the signal would reach the students (final users). However, a distance of 30 meters radius was observed on testing its coverage area.

User account and session management was effectively managed securely, thanks to the undoubted efficiency of MikroTik Router OS. The routing speed and packets transfer rate was very fast due to the configuration of the desktop computer's processor and RAM installed in the computer.

The university Internet authentication system was designed to wirelessly transmit internet services across the whole campus, especially within the classrooms, lecture halls and staff offices. It also offers free surfing of the department's rich mini portal website to the students. It also serves as a virtual e-notice board to students and lecturers for disseminating vital information across the campus using wireless Wi-Fi technology.

\section{Conclusions}

The performance of this work after testing met the design specifications. In view of all that we have experienced, learnt and put into practice, we deemed it necessary to enumerate the importance of WI-FI technological development to the national building.

\section{Recommendations}

Considering our discoveries during the course of execution of this work, the following recommendations are made:

i. Additional stages should be incorporated with the antenna design in the hotspot server of Federal University of Technology, Minna to boost its coverage on the campus by amplifying the signal the wireless PCI card is producing with an outdoor antenna and amplifier setup.

ii. A radius server services should be implemented and activated to boost the management and accounting of this hotspot wireless server.

\section{References}

[1] Douglas, E. C. (2009). Computer Networks and Internets. Cisco Research Inc. United States: Pearson Prentice Hall Publisher. 
[2] Nafiu, L. A. (2011). Unpublished Lecture Notes on NetCentric Computing. Federal University of Technology, Minna, Nigeria.

[3] Jamrich, J. P. \& Dan, O. (2001). Computer Concepts Illustrated Introductory Enhanced. United State: Gex Publishing Service.

[4] Christian, M. and Arnaud, A. (2004). Media Freedom Internet Cookbook. United States: OSCE Publishers.

[5] Wendell, O. (2004). Computer Networking: First Step.
United States: Cisco Press Publishers

[6] MikroTik Reference Manual available at www.wiki.mikrotik.com

[7] MikroTik Limited (2007). MikroTik Router OS Reference Manual.

[8] Encyclopedia of Internet available at www.en.wikipedia.com

[9] Federal University of Technology, Minna website available at www.futminna.edu.ng 